\title{
A Probabilistic Assessment for the Stress Corrosion Cracking Lifetime of Sensitized 304 Stainless Steel in Sodium Chloride Solutions
}

\author{
Gen NAKAYAMA, Masatsune AKASHI and Akira OHTOMO
}

Research Institute, Ishikawajima-Harima Heavy Industries Co., Ltd., Toyosu, Koto-ku, Tokyo, 135-91 Japan.

(Received on July 18, 1990; accepted in the final form on November 16, 1990)

\begin{abstract}
Since stress corrosion crack initiation / propagation process is essentially a stochastic one, a series of uniaxial constant load tests have been conducted on sensitized 304 stainless steel specimens in neutral chloride solutions to examine the effects of stress, temperature, crevice and chloride ion concentration on probability distribution of intergranular stress corrosion cracking lifetime. By examing the effects of various acceleration factors, the lifetime distribution can be satisfactorily presented by the exponential probability distribution model as that of sensitized stainless steels in hightemperature and high-purity water environment systems. The tendency of both the location parameter, i.e., lower limit of lifetime distribution, and the scale parameter, i.e., standard deviation of lifetime distribution, to increase with decreasing stress, temperature and chloride ion concentration, also the ratio of those two parameters is constant.
\end{abstract}

KEY WORDS: stress corrosion cracking; sensitized 304 stainless steel; neutral chloride solution; uniaxial constant load test; lifetime probability distribution; exponential distribution model.

\section{Introduction}

Corrosion phenomena are essentially stochastic in nature as Evans et al. ${ }^{1)}$ pointed out first. In as much as the initiation and the propagation process of the stress corrosion crack is essentially a stochastic process, an approach from the probabilistic viewpoint must be adopted in assessing the stress corrosion cracking lifetime quantitatively. That is to say, first a probability distribution law should be identified for the distribution of the lifetime the laboratory acceleration tests have revealed, then effects of various acceleration factors on the lifetime distribution should be clarified in terms of the distribution parameters.

Now, it has been demonstrated ${ }^{2-4}$ ) that the intergranular stress corrosion cracking lifetime distribution can well be represented by the exponential distribution model, which is;

$$
\begin{array}{rlrl}
F(t) & =1-\exp [-(t-\alpha) / \theta] ; & t \geqq \alpha \\
& =0 \quad ; \quad t<\alpha
\end{array}
$$

where, $F(t)$ : cumulative probability of crack initiation

$t:$ test duration

$\alpha$ : location parameter (=lower limit of lifetime distribution)

$\theta:$ scale parameter (=standard deviation of lifetime distribution).

Since the cumulative hazard, $H(t)$, is generally related to $F(t)$, the cumulative crack initiation probability, as in;

$$
F(t)=1-\exp [-H(t)],
$$

it should be lineally related to $t$ as in:

$$
H(t)=(t-\alpha) / 0 .
$$

Therefore, an arithmetic plot of $H(t)$ against $t$ should constitute an exponential probability diagram (the exponential hazard probability paper), where in the straight line gives the exponential distribution sought, the value of $t$ for $F(t)=H(t)=0$, or the $t$-axis cut of the line, gives the estimate for $\alpha$, and the line's tangent gives the estimate for $\theta$. Here, fitting of the straight line to the data can be performed most reasonably by the linear unbiased estimator method. $\left.{ }^{5}\right)$

Field failure data as well as laboratory acceleration test data have successfully been analyzed ${ }^{2-4,6)}$ by means of the exponential distribution model in sensitized stainless steel/high-temperature, high-purity water environment systems.

On the other hand, probabirity distribution for a type 304 stainless steel $/ \mathrm{MgCl}_{2}$ of a higher concentration system in the laboratory obtained test by Shibata, ${ }^{7)}$ showed that two- or three-parameter Weibull distribution could be applicable to failure time data under various conditions. This paper discusses the probability distribution of the stress corrosion cracking lifetime for a sensitized 304 stainless steel/ chloride solution of a lower concentration.

\section{Experimental}

With these notions for a background, and for a specific purpose of establishing a laboratory acceleration test to predict the stress corrosion cracking performance of a material in the real service environment planned, a series of uniaxial constant load tests have been conducted on sensitized 304 stainless steel in neutral chloride solution of a lower concentration to examine the effects of temperature, stress, crevice, and chloride ion concentration, on the probability 
distribution of intergranular stress corrosion cracking lifetime.

In the experiments, two 304 stainless steel pipings (SUS 304TP; 4-inch, Sch. 80), presented in Table 1 as $\mathrm{A}$ and $\mathrm{B}$ by the chemical composition, were used as subjected to a sensitization treatment of $1023 \mathrm{~K} / 1 \mathrm{~h}+$ $773 \mathrm{~K} / 24 \mathrm{~h}$, yielding different electrochemical potentiokinetic reactivation (EPR JIS G0580) ratio values as shown in Table 1. Bar tensile specimens (with a parallel portion of $5 \mathrm{~mm}$ in diameter and $10 \mathrm{~mm}$ in length) were machined out of these pipings. All the specimens had their parallel portions finished to polishing with 100-grid SiC emery paper, then were degreased with ethanol, and those which were intended for creviced effect testing were provided with an artificial crevice made of a PTFE filter paper. Fig. 1 presents a schematic of the test apparatus. The tests were repeated more than 10 times for a given set of conditions for probabilistic analyses.

The test environment was an aqueous solution of $\mathrm{NaCl}$, made up from deionized water and a reagent grade $\mathrm{NaCl}$ to a $\mathrm{pH}$ of 5.8 to 6.2 (no $\mathrm{pH}$ adjustment), and as may be seen in the figure, the environment chamber that surrounds the specimen is kept with the testing liquid of a given temperature and concentration supplied from the solution bath by $50 \mathrm{~cm}^{3} / \mathrm{min}$. The free corrosion potential of specimen was monitored during the whole test duration. The applied static load was 1.5-, 1.75-, or 2.0-times $S_{y}$ (design yield stress $=207 \mathrm{MPa}$ ), and the stress corrosion cracking lifetime was considered expended when the specimen fractured. After the completion of test, the fracture surface was examined visually and in a scanning electron microscope.

The test matrices are presented in Table 2 together with the results obtained.

\section{Results}

The free corrosion potential of the specimen re- mained unchangeable in the 0.2 to $0.3 \mathrm{~V}$ vs. SHE range, not giving rise to the customary increase ${ }^{8)}$ in the potential on film formation and decrease on macrocrack formation. The mode of cracking was always intergranular. These are shown in Figs. 2 and 3 as examples, respectively.

The effect of the applied stress on the lifetime distribution at $353 \mathrm{~K}\left(80^{\circ} \mathrm{C}\right)$ is shown in Fig. 4 for stresses $2.0 \times S_{y}, 1.75 \times S_{y}$, and $1.5 \times S_{y}$ by means of the exponential probability plot. Since the plotted lines are all sufficiently linear, it may be stated that the lifetime distribution can be approximated satisfactorily by the exponential distribution model. Also, the tendency of both the location parameter $\alpha$ and the scale parameter $\theta$ to increase with decreasing stress may be noted.

On the other hand, these two distribution parameters were found to increase with decreasing the temperature of the test solution. This is shown in Fig. 5 for an applied stress of $1.75 \times S_{y}$ as an example.

The effects of crevice are demonstrated by Fig. 6: although crevice does accelerate the initiation of stress corrosion crack, thereby decreasing these two parame-

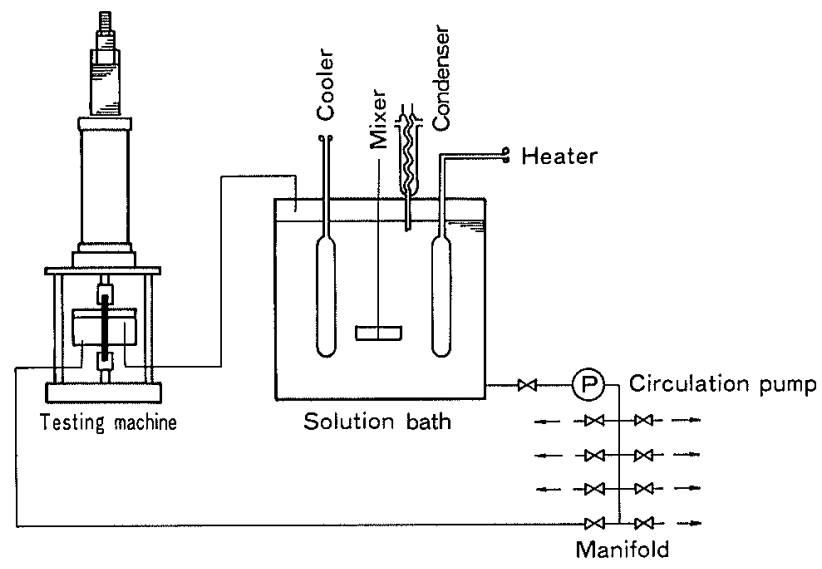

Fig. 1. Schematic of the test apparatus.

Table 1. Chemical compositions and EPR* values of specimens.

\begin{tabular}{ccccccccc}
\hline Materials & $\mathrm{C}$ & $\mathrm{Si}$ & $\mathrm{Mn}$ & $\mathrm{P}$ & $\mathrm{S}$ & $\mathrm{Ni}$ & $\mathrm{Cr}$ & EPR [\%] \\
\hline $\mathrm{A}$ & 0.045 & 0.50 & 1.60 & 0.019 & 0.005 & 9.10 & 18.16 & 38.2 \\
$\mathrm{~B}$ & 0.045 & 0.36 & 0.91 & 0.030 & 0.002 & 8.26 & 19.19 & 28.7 \\
\hline
\end{tabular}

* EPR : Electrochemical potentiokinetic reactivation.

Table 2. Results of uniaxial constant load tests.

\begin{tabular}{cccccccccc}
\hline No. & Materials & $\begin{array}{c}\text { Applied } \\
\text { stress }\end{array}$ & $\begin{array}{c}\text { Temper- } \\
\text { ature }\end{array}$ & Crevice* & $\begin{array}{c}\text { Cl- concent- } \\
\text { ration** }\end{array}$ & $\hat{\alpha}$ & $\hat{\theta}$ & $\hat{m}$ & $\hat{\mu}$ \\
\hline 1 & $\mathrm{~A}$ & $2.0 S_{y}$ & $80^{\circ} \mathrm{C}$ & - & $0.35 \%$ & 21.2 & 17 & 1.59 & 34 \\
2 & $\mathrm{~A}$ & $1.75 S_{y}$ & $80^{\circ} \mathrm{C}$ & - & $0.35 \%$ & 28.5 & 26.7 & 1.92 & 50 \\
3 & $\mathrm{~A}$ & $1.5 S_{y}$ & $80^{\circ} \mathrm{C}$ & - & $0.35 \%$ & 42.3 & 47 & 1.04 & 74 \\
4 & $\mathrm{~A}$ & $1.75 S_{y}$ & $50^{\circ} \mathrm{C}$ & - & $0.35 \%$ & 228 & 300 & 0.544 & 618 \\
5 & $\mathrm{~A}$ & $1.75 S_{y}$ & $30^{\circ} \mathrm{C}$ & - & $0.35 \%$ & 678 & 2470 & 0.99 & 2180 \\
6 & $\mathrm{~A}$ & $1.75 S_{y}$ & $30^{\circ} \mathrm{C}$ & - & $0.35 \%$ & 593 & 1130 & 1.96 & 1310 \\
7 & $\mathrm{~B}$ & $1.75 S_{y}$ & $80^{\circ} \mathrm{C}$ & $\bigcirc$ & $10^{3} \mathrm{ppm}$ & 485 & 391 & 1.42 & 718 \\
8 & $\mathrm{~B}$ & $1.75 S_{y}$ & $80^{\circ} \mathrm{C}$ & 0 & $10^{4} \mathrm{ppm}$ & 124 & 79.9 & 4.14 & 187 \\
9 & $\mathrm{~B}$ & $1.75 S_{y}$ & $80^{\circ} \mathrm{C}$ & 0 & $0.35 \%$ & 208 & 124 & 3.56 & 304 \\
\hline
\end{tabular}




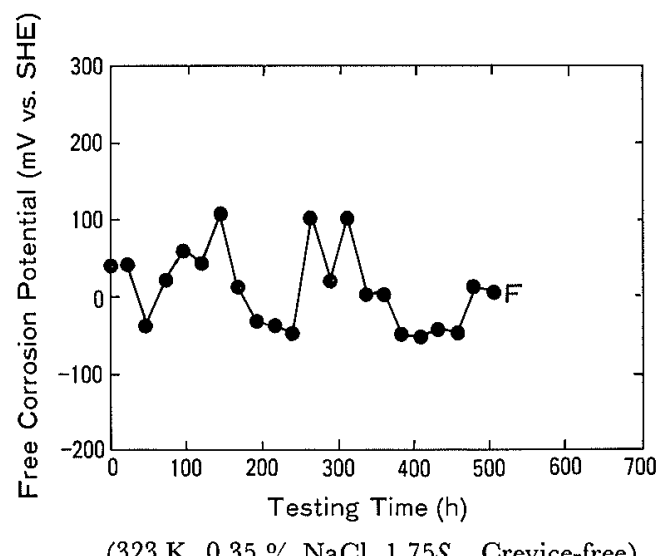

(323 K, $0.35 \% \mathrm{NaCl}, 1.75 \mathrm{~S}_{y}$, Crevice-free)

Fig. 2. Free corrosion potential change during the test.
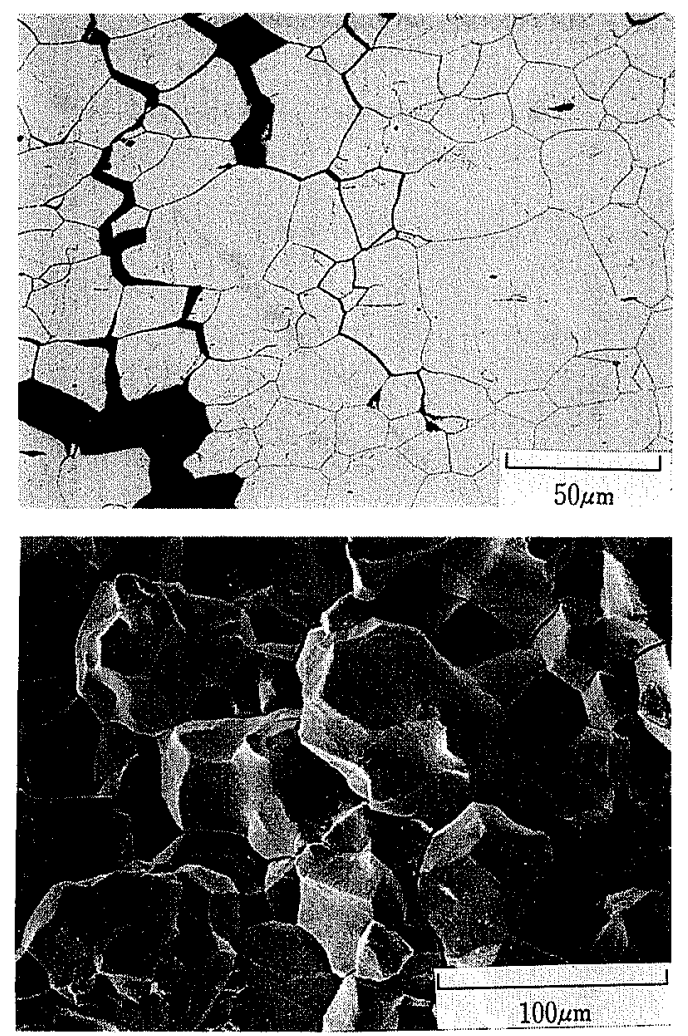

(353 K, $0.35 \% \mathrm{NaCl}, 1.5 S_{y}$, Crevice-free)

Fig. 3. Optical and scanning electron micrographs of a specimen tested.

ters, but the decrease is not very large.

Fig. 7 presents the effect of chloride ion concentration on the lifetime distribution of creviced specimens stressed at $1.75 \times S_{y}$ at $353 \mathrm{~K}\left(80^{\circ} \mathrm{C}\right)$. The two distribution parameters were found to increase with decreasing concentration.

Since the location parameter, i.e., the lower limit of the lifetime distribution, is quite important from the engineering viewpoint, Figs. 8 to 10 present the effects of the stress level, the test temperature or the chloride ion concentration on it, respectively. It is expected that the accumulation of these experimental data will lead to the reliable prediction of performances of materials in service environments from the laboratory acceleration test results.

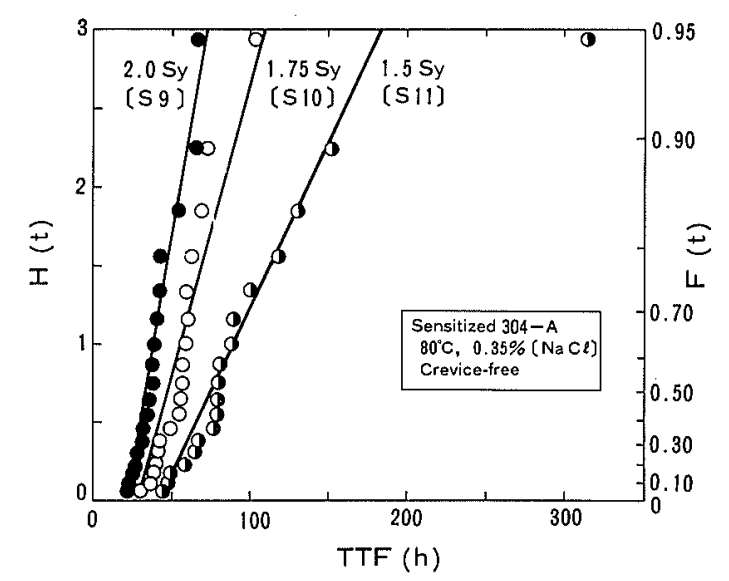

Fig. 4. Applied stress dependency of the lifetime distribution in $0.35 \% \mathrm{NaCl}$ at $353 \mathrm{~K}\left(80^{\circ} \mathrm{C}\right)$.

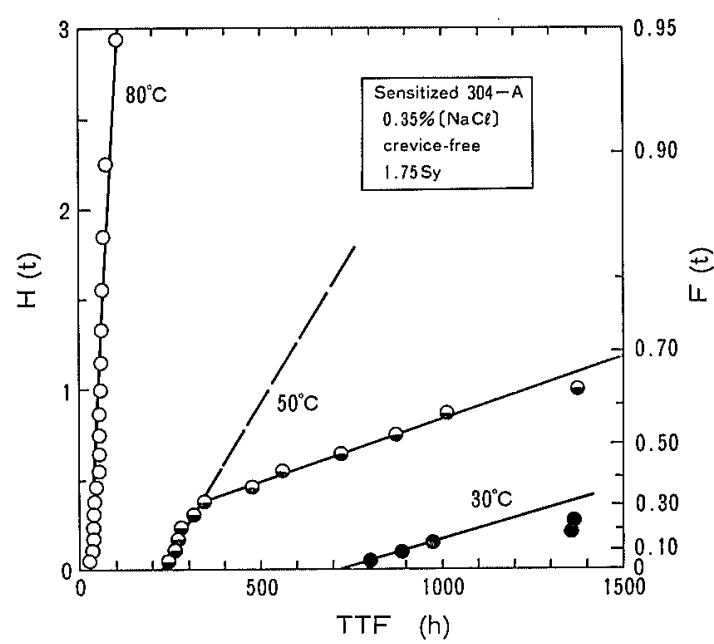

Fig. 5. Temperature dependency of lifetime distribution in $0.35 \% \mathrm{NaCl}$ at the applied stress level of $1.75 S_{y}$.

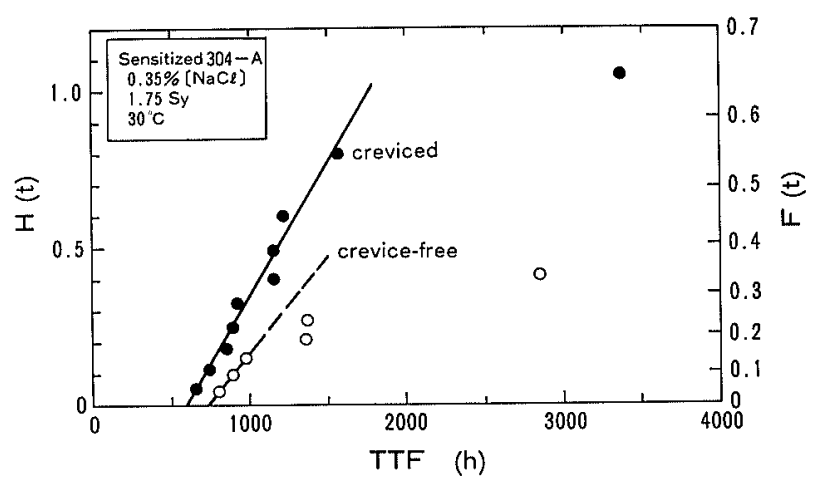

Fig. 6. Effect of crevice application on the lifetime distribution.

\section{Discussion}

\subsection{Relation between the Two Distribution Parameters}

The expectation that respective increases in the two distribution parameters are lineally related has duly been verified in Fig. 11: the two parameters may be regarded as remaining at a constant ratio of $\theta / \alpha=1.20$ within the realms of experiments, although the number of data points is not large enough to allow further analysis. Now, this observation compares admirably 


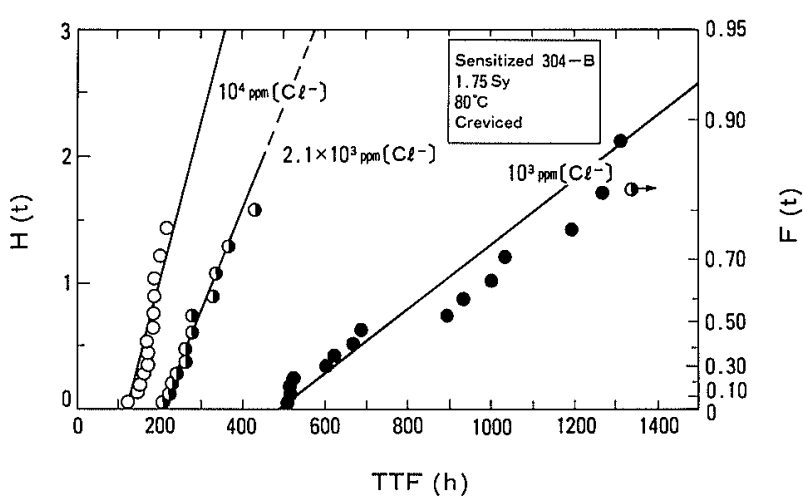

Fig. 7. Chloride ion concentration dependency of the lifetime distribution.

(h)

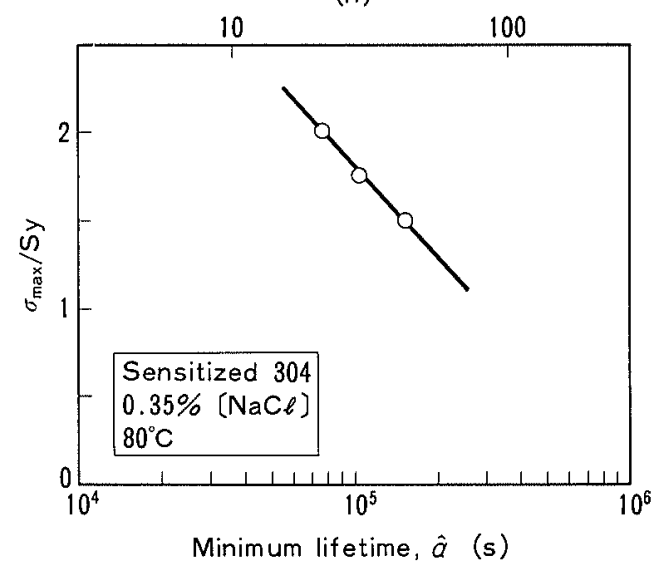

Fig. 8. Relation between the lower limit lifetime, $\hat{\alpha}$, and the applied stress level.

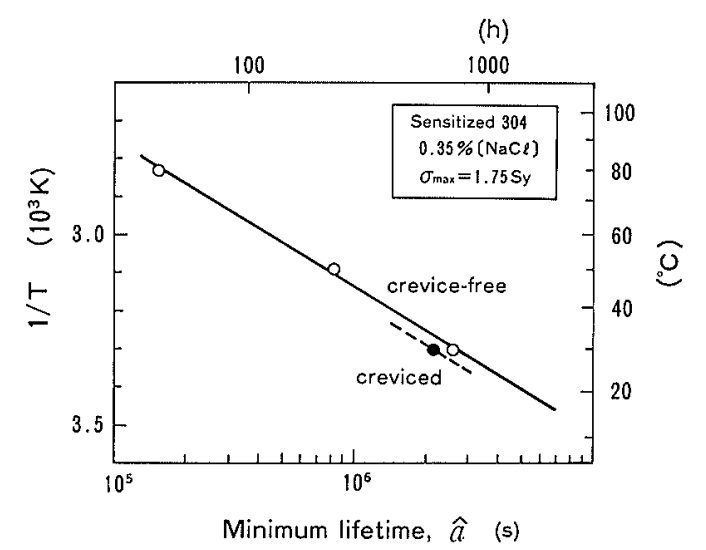

Fig. 9. Relation between the lower limit lifetime, $\hat{\alpha}$, and the test temperature.

with the case of intergranular stress corrosion cracking in sensitized stainless steel/high-temperature, high-purity water environment systems ${ }^{2-4,6)}$ presented in Fig. 12, even though the ratio of $\theta / \alpha$ was 6 in that case. This agreement should mean that the lifetime evaluation model ${ }^{4)}$ which was developed on the intergranular stress corrosion cracking behavior of sensitized stainless steels in high-temperature, high-purity water environment should apply to the lifetime prediction for the cases in stainless steel/neutral chloride environment systems. (h)

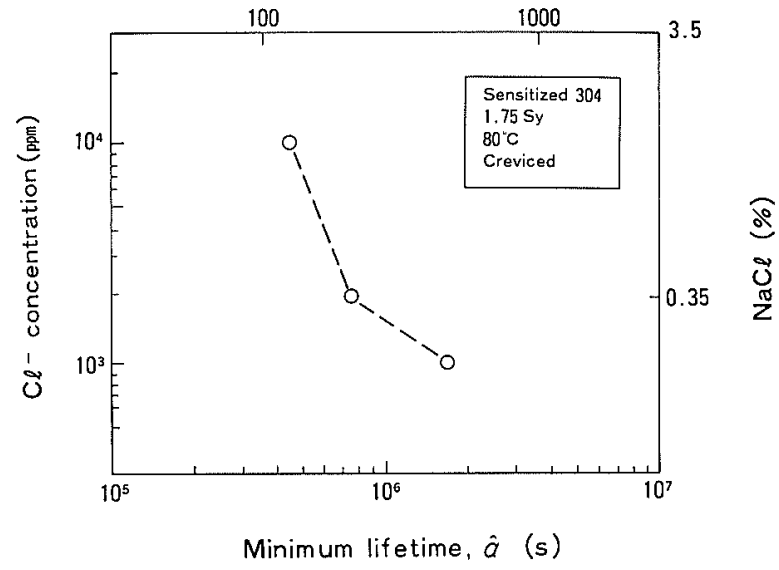

Fig. 10. Relation between the lower limit lifetime, $\hat{x}$, and the chloride ion concentration.

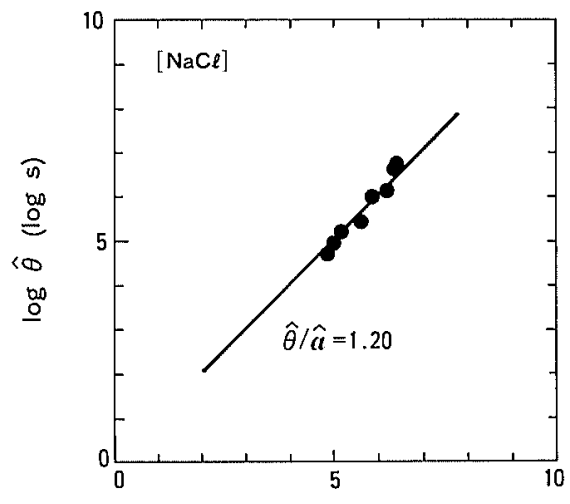

$\log \hat{a}(\log s)$

Fig. 11. Relation between the two distribution parameters in sensitized 304 stainless steel / neutral chloride environment systems.

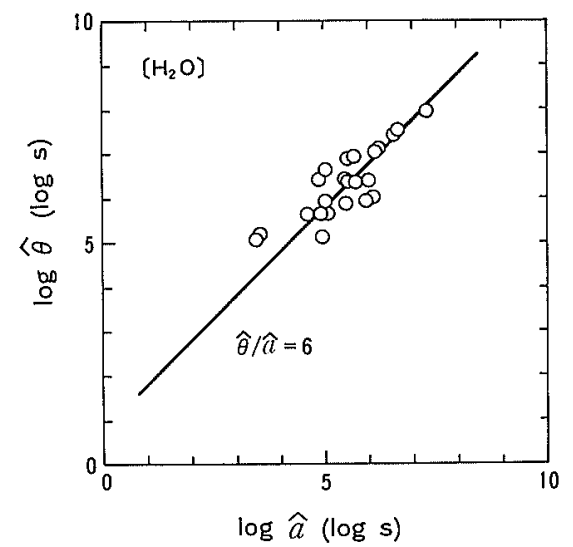

Fig. 12. Relation between the two distribution parameters in sensitized stainless steel / high-temperature, high-purity water environment systems.

\subsection{The Deviation from the Model on Longer Lifetime Side}

Another point of interest with these exponential probability plots obtained is the apparent appearance of a break point in the line on longer lifetime side as in the previous studies. ${ }^{2,3}$ ) Even though this seems to call for further investigation, only the shorter life- 
time side of line was considered here for estimation of the parameters.

Fig. 13 illustrates a model for initiation/propagation process of the stress corrosion crack discussed earlier. ${ }^{4)}$ Namely, numerous corrosion pits are first formed on the metal surface, and when they have grown to a certain size, small and non-progressive cracks are formed at their bottoms, ${ }^{2,9,10)}$ such that it is only after they have attained a certain size by mutual coalescence that they can grow steadily, though now as a main crack. ${ }^{9}$ According to this model, a lifetime of materials can be determined by the time in which a main crack has been formed though the coalescence of a number of microcracks to start its own propagation, meaning that a microcrack needs to find one or more other microcracks in its vicinity. Even though sites in which to form the microcracks, or the preceding corrosion pits, are available in great number, the probability of a microcrack having been initiated in the vicinity of an existing microcrack to make mutual coalescence feasible will be small enough to warrant the Poisson stochastic process model, justifying the presumption of the exponential distribution model for the time to coalescence of microcracks at the same time. ${ }^{2,3)}$ Namely;

$$
F_{C}(t)=1-\exp \left[-\left(t-\alpha_{C}\right) / 0_{C}\right]
$$

where, $F_{C}(t)$ : cumulative probability of crack coalescence.

On the other hand, the pit initiation process, or the microcrack generation process, can be approximated by the birth and death stochastic process model, ${ }^{11,12)}$ which is:

$$
\begin{aligned}
F_{l}(t)= & 1-\mu /(\lambda+\mu) \\
& -[\lambda /(\lambda+\mu)] \exp \left[-(\lambda+\mu)\left(t-\alpha_{I}\right)\right]
\end{aligned}
$$

where, $F_{I}(t)$ : cumulative probability of pit initiation

$\lambda$ : pit generation rate

$\mu$ : pit repassivation rate.

The probability distribution of the whole lifetime can consequently be modeled as the plural series combination of Eqs. (4) and (5), as schematized in Fig. 14.

\subsection{Application of the Weibull Probability Distribution Model}

The Weibull distribution model might be able to describe the lifetime distribution as well as the exponential distribution model. Namely;

$$
\begin{array}{rlrl}
F(t) & =1-\exp \left[-\{(t-\gamma) / \eta\}^{m}\right] ; & t \geqq \gamma \\
& =0 \quad ; \quad t<\gamma,
\end{array}
$$

where, $F(t)$ : cumulative probability of crack initiation

$m:$ shape parameter

$t:$ test duration

$\gamma$ : location parameter

(=lower limit of lifetime distribution)

$\eta$ : scale parameter.

The same set of data was analyzed with the Weibull distribution model. The distribution parameters were estimated by the linear unbiased estimate method due to Tsuge et al. ${ }^{13)}$ and are shown in Fig. 15 in terms of the scale parameter $m$ and the mean lifetime $\mu$. It will be noted that almost all the estimates of shape parameters, $m$, remain in the 0.5 to 2.0 range regardless of $\mu$, supporting $m$ to 1 (unit) in the Weibull distribution formula, thereby reducing it to the exponential distribution formula, and justifying the ap-

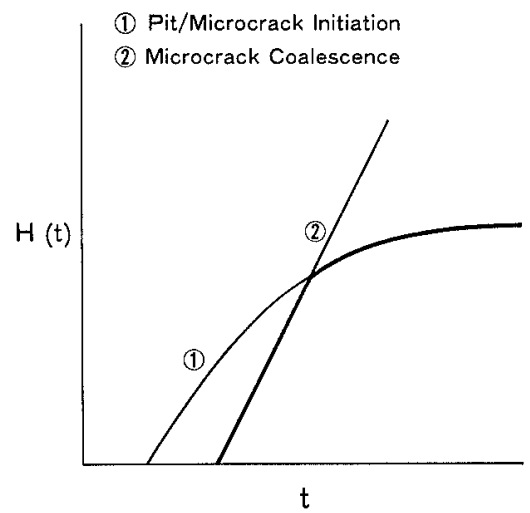

Fig. 14. Schematic of the probability plot for the stress corrosion crack life time due to the plural series combination of the stochastic processes of the pit/microcrack initiation and the microcrack coalescence.

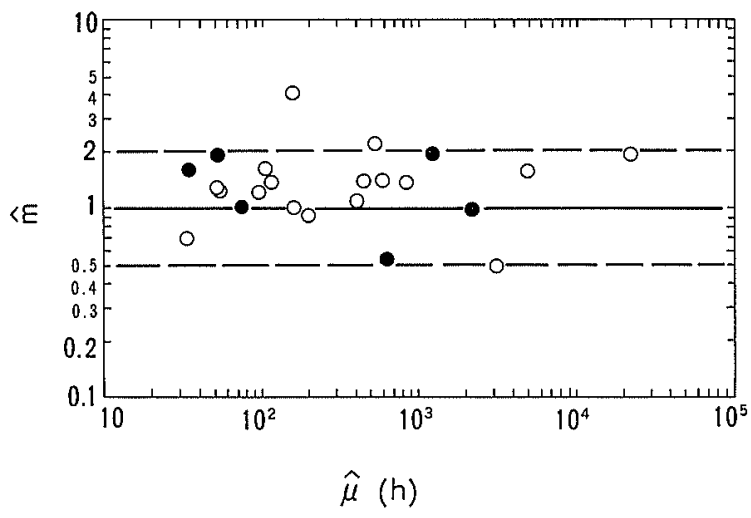

Fig. 15. Relation between the scale parameter $m$ and the mean lifetime $\mu$ in the Weibull distribution analysis.
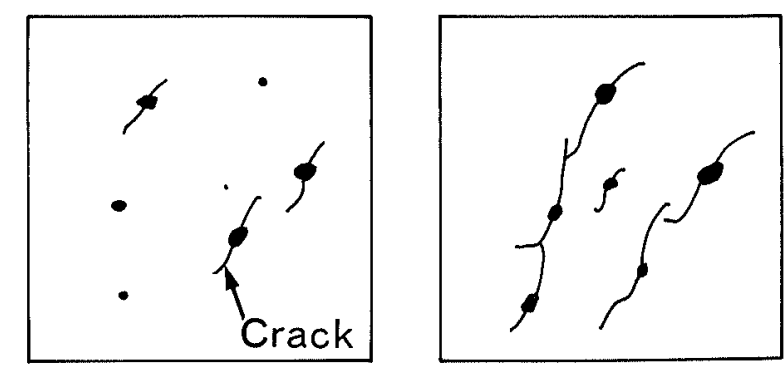

Fig. 13.

Schematic illustration of a stress corrosion crack initiation/propagation process model.

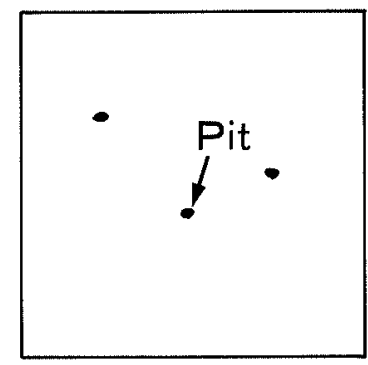


plication of the exponential distribution model.

\section{Summary and Conclusions}

The intergranular stress corrosion cracking behavior of sensitized 304 stainless steel in neutral chloride environment has been studied by means of uniaxial constant load tensile test. By examining the effects of various acceleration factors, it has been concluded:

(1) that the lifetime distribution can be satisfactorily presented by the exponential probability distribution;

(2) that the ratio of the location parameter $\alpha$ and scale parameter $\theta$ of the exponential distribution of lifetime is a constant; and

(3) therefore that the stochastic lifetime prediction method developed for austenitic stainless steels in high-temperature, high-purity water environment should apply equally well to those in chloride environment.

\section{Acknowledgments}

The authors gratefully acknowledge the aid extended to them in performing the stress corrosion testing by Messrs. T. Kenjyo, K. Miyokawa and $\mathrm{H}$. Murakami.

\section{REFERENCES}

1) U. R. Evans, P. B. Mears and P. E. Queneau: Engineering, $136(1933), 689$

2) M. Akashi, T. Kenjyo, S. Matsukura and T. Kawamoto: Corros. Eng. (Jpn.), 33 (1984), 628.

3) M. Akashi and A. Ohtomo: J. Soc. Mater. Sci., Jpn., 36
(1987), 59.

4) M. Akashi: "CBB Test Method for Assessing the Stress Corrosion Cracking Susceptibility of Stainless Steels in Hightemperature, High-purity Water Environments", in "Localized Corrosion", Current Japanese Materials Research, Vol. 4, ed. by F. Hine, K. Komai and K. Yamakawa, Soc. Mater. Sci., Japan, Elsevier, New York, (1988), 175.

5) M. Kowaka, H. Tsuge, M. Akashi, M. Masamura and H. Ishimoto: Introduction to Lifetime Prediction of Plant Materials-Application of Extreme Value Statistics to Corrosion, ed. by Japan Soc. Corros. Eng., Maruzen, Tokyo, (1984).

6) A. Okamoto, M. Akashi and M. Kitagawa: "Probabilistic Approach for the Defect Identification in BWR Pipings ", Pressure Vessel and Piping Conference, ASME Paper No. 87-PVP-30, (1987).

7) T. Shibata: "Probability Distribution of the Failure Time due to Stress Corrosion Cracking", in "Localized Corrosion ", Current Japanese Materials Research, Vol. 4, ed. by F. Hine, K. Komai and K. Yamakawa, Soc. Mater. Sci., Japan, Elsevier, New York, (1988), 175.

8) T. P. Hoar and J. G. Hines: J. Iron Steel Inst., 182 (1956), 124.

9) M. Akashi and T. Kawamoto: Corros. Eng. (Jpn.), 32 (1983), 9.

10) T. Fukuda and M. Akashi: Proc. of 33rd Joint Symp. on Corrosion Science and Technology, Japan Soc. Corros. Eng., Tokyo, (1986), 43.

11) T. Shibata and T. Takeyama: Proc. of the 8th Inter. Congr. Met. Corrosion, DECHEMA, Frankfurt/Main, (1981), 146 .

12) T. Shibata: Corros. Sci., 31 (1990), 413.

13) H. Tsuge, M. Akashi, K. Ikematsu, H. Nakajima, N. Saitoh and Y. Miyake: Proc. of the 73rd JSCE Symp., Japan Soc. Corros. Eng., (1988), 93; Micro-Computer Code "EVAN", Maruzen, Tokyo. 